14 International Monetary Fund. International financial statistics yearbook. Washington, DC International Monetary Fund, 1982

15 McKeown T. The role of medicine: dream, mirage or nemesis? New Jersey: Princeton University Press, 1980.

16 Illich I. The expropriation of health. London: Calder and Boyars, 1975.

17 Department of Health and Social Security. Report on confidential enquiries into maternal death in England and Wales 1976-8. Reports on health and social subjects. No 26. London: HMSO, 1982

18 New York Academy of Medicine, Committees on Public Health Relations. Maternal mortality in New York City: a study of all puerperal deaths 1930-1932. New York: The Commonwealth Fund 1933.

19 Ryan GM, Pettigrew AH, Fogerty S, Donalue CL Jr. Regionalizing perinatal health services in Massachusetts. N Engl f Med 1977;296:228-30

20 Anderson OW. Health care: can there be equity? The United States, Sweden and England. New York: John Wiley and Sons, 1972.

1 Cramer DW. Uterine cervix. In: Schothenfeld D, Fraumeni JF, eds. Cancer epidemiology and prevention. Philadelphia: WB Saunders Company, 1982:881-900.

22 Wynder EL, Hiranyoma T. Comparative epidemiology of cancers of the United States and Japan. Prev Med 1977;6:567-94.

23 Devesa SS, Silverman D'T. Cancer incidence and mortality trends in the United States: 1935-74. Journal of the National Cancer Institute 1978;60:545-74.

24 Green SB. Survival for lymphomas and leukemias. Washington, DC: DHEW, 1978. (NIH 78-1546.)

25 Feinstein AR, Stern EK, Spagnuola M. The prognosis of acute rheumatic fever. Am Heart $\mathcal{f}$ 1966;111:533-43.

26 Gordis L. Effectiveness of comprehensive programs in preventing rheumatic fever. $N$ Engl $\mathrm{J} \mathrm{Med}$ $1973 ; 289: 331-5$

27 Gordon T, Thorn T. The recent decrease in CHD mortality. Prev Med 1975;4:115-25.

28 Clayton DG, Taylor D, Shaper AG. Trends in heart disease in England and Wales, 1950-1973. Health Trends 1977;9:1-6.
29 Raguveer-Saran MK, Keddie NC. The falling incidence of appendicitis. Br f Surg 1975;67:681. 30 Noer T. Decreasing incidence of acute appendicitis. Acta Chir Scand 1975;141:431-2.

31 Johnston RF, Wilderick KH. "State of the art" review. The impact of chemotherapy on the care of patients with tuberculosis. Am Rev Respir Dis 1974;109:636-46.
pistion

32 British Thoracic and Tuberculosis Association. A survey of tuberculosis mortality in England and Wales in 1968. Tubercule 1971;52:1

33 Clarke EA, Anderson TW. Does screening for "PAP" smears help prevent cervical cancer? Lancet $1972 ;$;i: 1 -4.

34 Task Force appointed by Conference of Deputy Ministers of Health. Screening for carcinoma of the cervix. Can Med Assoc f 1976;114:1013-26.

35 Aisenberg AC. The staging and treatment of Hodgkin's disease. N Engl F Med 1978;299:1228-32. 36 Kaplan HS. Hodgkin's disease. 2nd ed. Cambridge, Massachusetts: Harvard University Press, 1980:548-97.

37 Management Committee of Australian Therapeutic Trial in Mild Hypertension. Report. Lancet $1980 ;: 1261-7$.

38 Veterans Administration Co-operative Study Group on Antihypertensive Agents. Effects of treatment on morbidity in hypertension. II. Results in patients with diastolic blood pressure averaging 90-through $114 \mathrm{mmHg}$. JAMA 1970;213:1143-52.

39 Hypertension Detection and Follow-up Program Co-operative Group. Five year findings of the hypertension detection and follow-up program. III. Reduction in stroke incidence among persons with high blood pressure. FAMA 1982;247:633-8

40 Ranshoff DF, Gracie WA, Wolfenson LB, Newhamser D. Prophylactic cholecystectomy or expedient management for silent gallstones. A decision analysis to assess survival. Ann Intern Med 1983;99:199-204.

41 Fitzpatrick G, Newtra R, Gilbert JP. Cost effectiveness of cholecystectomy for silent gallstone. In : Bunker JP, Barues BA, Mostellen F, eds. Cost risks and benefits of surgery. New York: Oxford University Press, 1977:201-76.

(Accepted 20 November 1985

\title{
Antiglomerular basement membrane antibody mediated disease in the British Isles 1980-4
}

\author{
CAROLINE O S SAVAGE, C D PUSEY, CHRISTINE BOWMAN, A J REES, \\ C M LOCKWOOD
}

\begin{abstract}
Clinical and pathological data on 71 patients from throughout the British Isles who developed antiglomerular basement membrane antibody mediated nephritis in the period $1980-4$ were studied. Two principle patterns of disease were recognised: young men presenting in their 20s with Goodpasture's syndrome (glomerulonephritis and lung haemorrhage) and women presenting in their 60s with glomerulonephritis alone. The effect of treatment on prognosis of a total of 108 patients was also reviewed (the 71 patients plus patients seen before 1980 at Hammersmith Hospital). Treatment with prednisolone, cytotoxic drugs, and plasma exchange hastened the time to clearance of autoantibody and improved the outlook of patients who were not dependent on dialysis and those with lung haemorrhage.
\end{abstract}

\section{Introduction}

Antiglomerular basement membrane antibody mediated disease is characterised by the formation and linear deposition of anti-

\footnotetext{
Medical Research Council Clinical Immunology Research Group, Renal Unit and Department of Medicine, Royal Postgraduate Medical School, Hammersmith Hospital, London W12 0HS

CAROLINE O S SAVAGE, MRCP, MRC research fellow

C D PUSEY, MRCP, senior lecturer and honorary consultant physician CHRISTINE BOWMAN, BSC, research officer

A J REES, FRCP, consultant nephrologist and honorary senior lecturer C M LOCKWOOD, FRCP, senior lecturer and honorary consultant physician

Correspondence to: Dr Savage.
}

glomerular basement membrane autoantibodies along the glomerular basement membrane, resulting in injury to tissues that is clinically manifested by acute glomerulonephritis. In some patients antibodies are also deposited on the alveolar basement membrane, causing lung haemorrhage (Goodpasture's syndrome). The pathogenetic role of antiglomerular basement membrane autoantibodies was established by Lerner et al in 1967 using transfer experiments in which subhuman primates developed glomerulonephritis after injection of human antiglomerular basement membrane antibodies obtained from serum or eluted from the glomerular basement membrane of renal homogenates of patients with the disease. Subsequently, assays have been developed that detect circulating antiglomerular basement membrane autoantibodies, allowing rapid diagnosis and monitoring of disease activity. ${ }^{2}$

A sensitive radioimmunoassay has been available in our laboratory since 1980 and is used to test serum samples from patients sent by doctors throughout the British Isles for the presence of antiglomerular basement membrane antibodies on an emergency or routine basis. ${ }^{3}{ }^{4}$ We have therefore been able to study many patients who had antiglomerular basement membrane antibody mediated nephritis and have conducted a survey of the 83 patients who developed antiglomerular basement membrane antibody mediated nephritis from June 1980 to June 1984 and whose serum samples were sent to our laboratory to be assayed for antiglomerular basement membrane antibodies.

Data on 71 patients were collected and used to determine the clinical and laboratory features at presentation. Furthermore, to study the effect of treatment on prognosis we reviewed the outcome of 49 consecutive patients treated at Hammersmith Hospital since 1974 , when treatment with intensive plasma exchange was started, and 59 patients in whom the diagnosis was confirmed by our assay but who were treated at other hospitals. 


\section{Patients and methods}

A sensitive solid phase radioimmunoassay for circulating antiglomerular basement membrane antibodies has been available in our laboratory since $1980 .{ }^{34}$ Briefly, polyvinylchloride microtitre plates are coated with human glomerular basement membrane solubilised with collagenase at a concentration of $15 \mu \mathrm{g} / \mathrm{ml}$ in complement fixation diluent $\mathrm{pH} 7 \cdot 2$ by overnight incubation at $4^{\circ} \mathrm{C}$. After washing with complement fixation diluent containing $0 \cdot 1 \%$ Tween 20 plates are incubated with control (normal and reference positive) or test serum samples (diluted $1 / 8$ in complement fixation diluent plus Tween 20) for one hour at $37^{\circ} \mathrm{C}$. After further washing with complement fixation diluent plus Tween 20) bound IgG antihuman glomerular basement membrane antibodies are detected by incubation with antihuman IgG labelled with iodine-125 (specific activity $3 \mu \mathrm{Ci} / \mu \mathrm{g}$ (111 $\mathrm{MBq} / \mathrm{g}$ ); $2 \times 10^{5}$ counts per minute/well) in complement fixation diluent plus Tween 20 ) containing $0 \cdot 1 \%$ bovine serum albumin at $37^{\circ} \mathrm{C}$ for one hour. All specimens and minor abnormalities only were found in three. Crescents were present in 57 of 63 specimens, and in 43 of 49 biopsy specimens in which the number of affected glomeruli was given the percentage exceeded $60 \%$.

Direct immunofluorescence studies were performed on 53 biopsy specimens, including the specimens that showed little abnormality on ligh microscopy. Linear deposition of IgG along the glomerular basement membrane was present in $\mathbf{5 0}$ biopsy specimens, and roughly half of these showed concurrent linear deposition of C3. Deposition of linear IgA and C3 without IgG was present in one biopsy specimen, linear $\operatorname{IgM}$ and C3 in another, and linear C3 only was reported in a third.

The seasonal incidence of disease was investigated using the request date for those radioimmunoassays performed between June 1980 and June 1984 that were positive for antiglomerular basement membrane antibodies. These seasonal incidences were as follows: four patients were positive for antiglomerular basement membrane antibodies in January, seven in Feb-

TABLE I-Age and sex distribution of patients presenting with glomerulonephritis alone or Goodpasture's syndrome

\begin{tabular}{|c|c|c|c|c|c|c|c|c|}
\hline & \multicolumn{8}{|c|}{ Age (years) } \\
\hline & $0-10$ & $11-20$ & $21-30$ & $31-40$ & $41-50$ & $51-60$ & $61-70$ & $71-80$ \\
\hline \multicolumn{9}{|l|}{ No of patients with glomerulonephritis $(n=46)$ : } \\
\hline \multirow{3}{*}{\multicolumn{9}{|c|}{$\begin{array}{l}\text { No of patients with Goodpasture's syndrome }(\mathrm{n}=25) \text { : } \\
\text { Men }\end{array}$}} \\
\hline & & & & & & & & \\
\hline & & 1 & 6 & 3 & 4 & 1 & 3 & 1 \\
\hline
\end{tabular}

volumes are $100 \mu \mathrm{l}$. Plates are then washed with complement fixation diluent plus Tween 20), drained, and counted in an LKB 1260 multichannel gammacounter. Binding of test serum samples is expressed as percentage binding of the reference positive serum sample from a linear regression curve for standardised positive and negative serum samples used in each assay. Binding of normal serum is $7 \cdot 4-12 \cdot 8 \%$ (mean (2 SD)) binding of the reference positive serum.

Between June 1980 and June 1984 we received 1100 requests for the assay from doctors throughout the British Isles. Antiglomerular basement membrane antibodies were detected in the serum samples of 83 patients; 71 were treated at their local renal units and 12 were referred to our hospital for further management. Clinical and laboratory details of the 71 patients treated outside this hospital were requested by questionnaire: information was obtained on 59 patients. Data on these 59 patients, together with data obtained by reviewing the records of the 12 patients treated at our hospital from 1980 to 1984, were combined to give a representative picture of antiglomerular basement membrane antibody mediated disease in the British Isles.

To study the effect of treatment on prognosis we reviewed the results of 49 patients treated consecutively at this hospital since 1974 and compared these with the results of 59 of the 71 patients treated outside this hospital since 1980 for whom data were available from the survey.

\section{Results}

\section{CLINICAL AND LABORATORY FEATURES}

Forty one men and 30 women presented in the period 1980-4. Sixty nine patients were white, one was negroid, and one was Asian. The overall mean (range) age of these patients was $47 \cdot 8(17-75)$ years: mean age of men was 45 years and women 51.6 years. The age distribution of these patients was as follows: two patients were aged 10-19 years, 14 aged 20-29, 10 aged 30-39, seven aged 40-49, 12 aged 50-59, 18 aged 60-69, and eight aged 70-79. The age distribution of the patients was thus bimodal with a peak in young adult life and a second peak in the 60 year old age group. The occupations of the patients were generally unremarkable, and only three patients had a history of possible exposure to inhaled hydrocarbons.

All patients had raised antiglomerular basement membrane antibody titres. There was a significant difference between antibody titres in patients who were not dependent on dialysis $(n=19)$ with plasma creatinine concentrations greater and less than $500 \mu \mathrm{mol} / 1(5.7 \mathrm{mg} / 100 \mathrm{ml}$ ) (MannWhitney $U$ test, $p<0.01$; fig 1 ). The antibody titre correlated best with the plasma creatinine concentration at presentation in these patients (Spearman rank correlation coefficient, $\left.r_{s}=0.6088, p<0.02\right)$ and did not correlate with plasma creatinine concentration at presentation in patients who required dialysis.

Histology was examined in 62 renal biopsy specimens and material from necropsy for one patient. Proliferative changes were noted in 59 biopsy

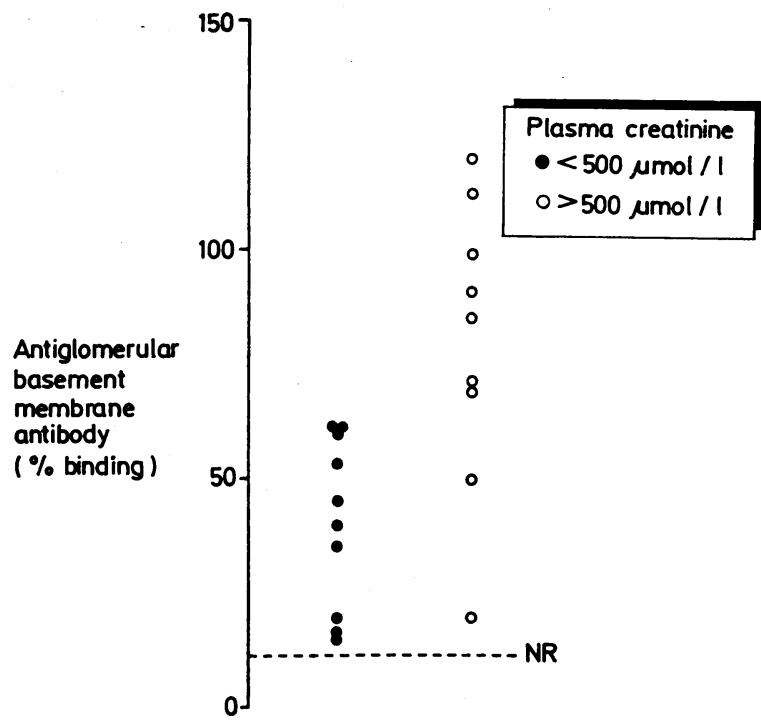

FIG 1-Relation of antiglomerular basement membrane antibody titres (measured in \% binding in radioimmunoassay) in patients not dependent on dialysis $(n=19)$ to plasma creatinine concentrations at presentation. $\mathrm{NR}=$ Normal range.

Conversion: SI to traditional units-Plasma creatinine: $1 \mu \mathrm{mol} / 1$ $\approx 0.01 \mathrm{mg} / 100 \mathrm{ml}$.

ruary, seven in March, 10 in April, nine in May, eight in June, four in July, six in August, six in September, two in October, three in November, and five in December. This suggests a peak incidence of disease in spring and early summer. This was later confirmed (A M Davison, personal communication) using the time of renal biopsy as reported to the Medical Research Council glomerulonephritis registry from January to December 1982 of those patients in whom deposition of antiglomerular basement membrane antibody was detected by direct immunofluorescence. These results were as follows: deposition of antiglomerular basement membrane was detected in two patients in January, three in February, four in March, five in April, eight in May, six in June, one in July, one in August, two in September, one in October, two in November, and one in December. No seasonal incidence was shown in the time of renal biopsy in patients with crescentic glomerulonephritis who did not have linear deposits of immunoglobulin along the glomerular basement membrane (A M Davison: Seasonal incidence of glomerulonephritis: findings of UK Medical Research Council's 
glomerulonephritis registry; abstract given in Proceedings of Ninth International Congress on Nephrology, 1984:84A).

At presentation 52 out of 71 patients were dependent on dialysis; 15 had a plasma creatinine concentration $>120 \mu \mathrm{mol} / \mathrm{l}(1.4 \mathrm{mg} / 100 \mathrm{ml})$ and four $<120 \mu \mathrm{mol} / \mathrm{l} ; 24$ had overt lung haemorrhage with plasma creatinine concentration $>120 \mu \mathrm{mol} / \mathrm{l}$ and one $<120 \mu \mathrm{mol} / 1$. In no patient was disease confined to the lungs. Forty six patients presented with glomerulonephritis alone (table I). The sex ratio was roughly equal, but there was a bimodal age distribution, and the number of patients older than 50 years exceeded those less than 50 years by $1 \cdot 5: 1$. Furthermore, women predominated in the older age group ( $>50$ years), but men predominated in the younger age group ( $<50$ years). Twenty five patients seen since June 1980 presented with both glomerulonephritis and lung haemorrhage (Goodpasture's syndrome) (see table I). Most were men (men:women ratio 2:6:1). Two thirds of the patients were less than 50 years old, most being in their $20 \mathrm{~s}$; there was a second and much smaller peak of patients in their $60 \mathrm{~s}$.

At presentation hypertension was unusual (in 10 of the 71 patients with antiglomerular basement membrane antibody mediated nephritis). A few patients had systemic features-that is, arthritis (six patients), myalgia (six), and vasculitic rash (five). A few patients (four) had neurological features manifested by epileptiform fits, personality disturbances, or retinitis in the presence of normal blood pressure. Coeliac disease developed in one patient simultaneously with antiglomerular basement membrane antibody mediated nephritis, an association that has previously been described in a single patient. ${ }^{6}$ Ulcerative colitis developed in a further patient three months after the onset of antiglomerular basement membrane antibody mediated disease. One patient had Staphylococcus epidermidis endocarditis at presentation.

\section{TREATMENT}

Data on treatment for 59 patients obtained by postal survey (group 1) and for 49 patients treated consecutively at our hospital since 1974 (group 2) were reviewed. Most patients were treated with various combinations and dosages of steroids, cytotoxic drugs (azathioprine or cyclophosphamide), and plasma

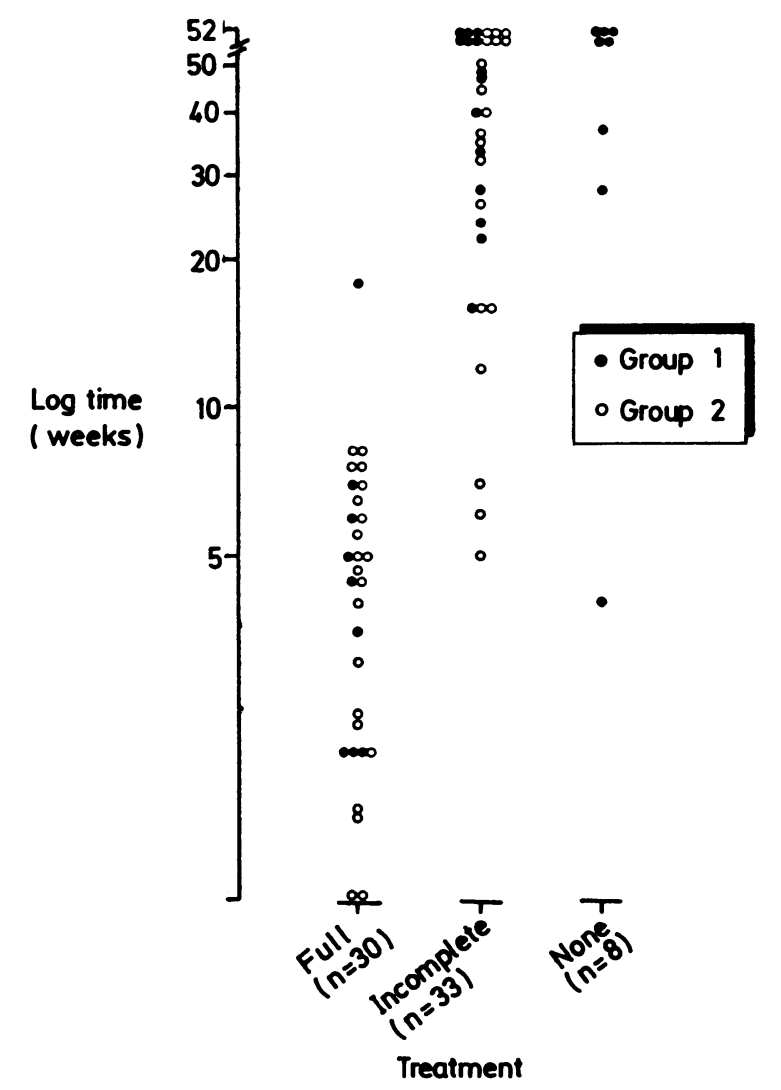

FIG 2-Time to clearance of antiglomerular basement membrane antibody against treatment regimen.

TABLE II-Effect of treatment at eight weeks on renal function in patients with antiglomerular basement membrane antibody mediated disease in groups 1 and 2 . Values are numbers of patients

\begin{tabular}{|c|c|c|c|c|c|}
\hline \multicolumn{3}{|c|}{ Presentation } & \multicolumn{3}{|c|}{ Outcome at eight weeks } \\
\hline $\begin{array}{c}\text { Plasma } \\
\text { creatinine } \\
(\mu \mathrm{mol} / \mathrm{l})\end{array}$ & $\begin{array}{c}\text { No of } \\
\text { patients }\end{array}$ & $\begin{array}{l}\text { Received } \\
\text { treatment }\end{array}$ & Improved & $\begin{array}{c}\text { Required } \\
\text { dialysis }\end{array}$ & Died \\
\hline \multicolumn{6}{|c|}{ Group $1(n=59)$} \\
\hline Normal & 3 & 2 & 3 & & \\
\hline$<600$ & 5 & 5 & 2 & 2 & 1 \\
\hline$>600$ & 7 & 7 & & 4 & 3 \\
\hline Dialysis dependent & 44 & 33 & & 33 & 11 \\
\hline \multicolumn{6}{|c|}{ Group $2(n=49)$} \\
\hline Normal & 4 & 4 & 3 & & 1 \\
\hline$<600$ & 15 & 15 & 13 & 2 & \\
\hline$>600$ & 5 & 5 & 1 & 4 & \\
\hline Dialysis dependent & 25 & 25 & & 18 & 7 \\
\hline
\end{tabular}

Conversion: SI to traditional units-Plasma creatinine: $1 \mu \mathrm{mol} / 1 \approx 0 \cdot 01 \mathrm{mg} / 100 \mathrm{ml}$.

exchange. Eight patients in group 1 , however, received no immunosuppressive treatment or plasma exchange.

Patients were subdivided depending on whether they received a full course of treatment. The definition of full treatment was based on our hospital's treatment regimen at the time of this study, as described elsewhere. ${ }^{7}$ Briefly, full treatment comprised cyclophosphamide $3 \mathrm{mg} / \mathrm{kg}$ body weight/day (rounded down to the nearest $50 \mathrm{mg}$ ) for a total of eight weeks or at least until circulating autoantibody cleared, provided that the white cell count remained above $3.5 \times 10^{9} / 1$ and there was no overt infection. Patients less than 55 years also received azathioprine $1 \mathrm{mg} / \mathrm{kg}$ body weight/day. Prednisolone treatment was started at $60 \mathrm{mg} /$ day and gradually reduced. In addition, at least 14 daily four litre exchanges for plasma protein fraction were given, more if antibody concentrations were still raised after these two weeks.

In all but one of the 30 patients who received full treatment circulating antiglomerular basement membrane antibodies cleared within eight weeks, irrespective of the initial antibody titre. Figure 2 shows the effect of treatment on time to clearance of antibody in 71 patients in whom data on follow up were available. Three patients who received incomplete treatment, albeit with low antibody concentrations, also cleared the antibody within eight weeks. Interestingly, in one patient the autoantibody cleared spontaneously in four weeks.

Renal function improved after treatment in most patients (21 out of 27) whose presenting plasma creatinine concentration was normal or less than $600 \mu \mathrm{mol} / 1(6-8 \mathrm{mg} / 100 \mathrm{ml}) ; 15$ of the 21 patients whose renal function improved after treatment received full treatment, and one patient's renal function improved spontaneously (table II). Two of the 27 patients with plasma creatinine concentrations $>600 \mu \mathrm{mol} / \mathrm{l}$ died from lung haemorrhage, and the remaining four patients progressed to end stage renal failure (despite full treatment being given to two patients). The outcome for renal function in patients whose plasma creatinine concentration was $>600 \mu \mathrm{mol} / \mathrm{l}$ was less good: only one out of 12 patients improved. No patient who was dependent on dialysis at presentation recovered worthwhile renal function.

Overall, 56 of the 108 patients in both groups developed lung haemorrhage and all received some form of treatment. Fourteen out of 18 patients in group 1 improved as did 33 out of 38 in group 2; the overall mortality from this cause was $8 \cdot 5 \%$.

The mortality at eight weeks when cytotoxic treatment would normally be withdrawn was 15 out of $59(25 \%)$ in group 1 and eight out of $49(16 \%)$ in group 2. Less than half of deaths in group 1 were due to lung haemorrhage or 
infection, but the converse was true in group 2 . These differences may reflect the older mean age of patients in group 1 and the larger number of patients with lung haemorrhage in group 2.

\section{Discussion}

Over a four year period from June 1980 to June 1984 the diagnosis of antiglomerular basement membrane antibody mediated nephritis was confirmed in 83 patients whose serum samples were sent to our laboratory to be assayed for antiglomerular basement membrane autoantibodies, an incidence of roughly 20 cases each year. This is almost certainly an underestimate as the diagnosis in some patients may have been entirely based on the results of immunofluorescence studies of renal tissue without recourse to the serum assay. Furthermore, the diagnosis may have been overlooked in other patients with mild disease manifested by urinary abnormalities alone in whom renal biopsies may not have been performed. Obviously the detection rate of the disease in such instances will vary between centres depending on the criteria used to decide when to perform renal biopsies in patients with acute glomerulonephritis.

The measurement of circulating antiglomerular basement membrane antibodies using a rapid radioimmunoassay ${ }^{3}{ }^{4}$ not only allows prompt diagnosis but also allows antibody concentrations to be monitored and treatment adjusted accordingly_-for example, plasma exchange may be safely withdrawn when antibody concentrations reach a baseline and continued monitoring allows plasma exchange to be reintroduced if rebound occurs. Confirmation of the absence of circulating antiglomerular basement membrane antibodies before renal transplantation reduces the likelihood of recurrence of the disease within the graft. Interestingly, antibody concentrations have been found to correlate with presenting plasma creatinine concentrations in patients who are not dependent on dialysis, supporting their pathological role. ${ }^{8}$ Later in the disease, as judged by the need for dialysis, there is no correlation between antibody concentrations and renal function perhaps because other factors such as amplification of injury to tissues by infection and overload of fluid may come into play. ${ }^{9}$

The diagnostic adjunct to the radioimmunoassay is direct immunofluorescence of renal tissue, which detects the linear deposition of immunoglobulin, predominantly IgG, along the glomerular basement membrane and tubular basement membrane. In our patients studied since 1980 linear IgG was detected in all but three, one of whom had linear $\operatorname{IgM}$ with $\mathrm{C} 3$, one had linear $\operatorname{IgA}$ with $\mathrm{C} 3$, and the other had linear C3 alone. Interestingly, these three patients had raised circulating concentrations of antiglomerular basement membrane antibodies of the IgG class. In the patient with deposition of linear IgA circulating antiglomerular basement membrane antibodies of the IgA class were also detected (C Bowman, unpublished results). Deposition of the IgA class alone has been noted once previously. ${ }^{10}$ The immunoglobulin deposits were accompanied by complement components in about half the cases, suggesting a role for activation of the classical pathway in these patients.

The classical picture of antiglomerular basement membrane antibody mediated nephritis portrays a young man with Goodpasture's syndrome. In the 1973 series reported by Wilson and Dixon 32 patients had Goodpasture's syndrome and 21 patients had glomerulonephritis alone with more men than women in both groups. "In a later series the sex ratio of patients with glomerulonephritis alone was more nearly equal, and most women in this group were in their 50s and 60s. ${ }^{12}$ This later series resembles our own experience more closely, but we found a larger proportion of patients (half) presenting with glomerulonephritis alone. The classical picture of the young man with lung haemorrhage appears to be complemented by a group of elderly women presenting with glomerulonephritis alone. The apparent pattern of disease has been and remains affected by such variables as criteria used for diagnosis of lung haemorrhage, availability of the serum assay for antiglomerular basement membrane antibodies, and the readiness of doctors to perform renal biopsies.

The mean time to clearance of autoantibody in untreated patients has previously been reported as 14 months. ${ }^{12}$ That antibody generally persists longer than two months is shown by data from our untreated patients in whom it persisted for an average of 11 months (Flores et al, manuscript in preparation). Measurement of circulating antibody concentrations in both the postal survey group and our hospital cohort indicated that intensive treatment with prednisolone, cytotoxics, and plasma exchange controls autoantibody production within eight weeks. Such immunosuppressive treatment also improves the outlook for renal function compared with historical controls. Thus in the 1973 series of Wilson and Dixon $13 \cdot 2 \%$ of patients who were not dependent on dialysis at presentation recovered or maintained renal function ${ }^{11}$ compared with $33 \%$ of patients in group 1 and $71 \%$ in group 2 in this study. Notably none of the patients who were dependent on dialysis at presentation recovered renal function even if they received full treatment. Oligoanuric patients, however, may occasionally recover $^{13}$; we know of a 75 year old patient who presented with a plasma creatinine concentration of $1000 \mu \mathrm{mol} / 1(11.3 \mathrm{mg} / 100 \mathrm{ml})$ and was dependent on dialysis (renal biopsy was not performed) who recovered sufficient renal function to remain independent of dialysis (F P Marsh, personal communication). Nevertheless, our present policy is to withhold potentially toxic treatment from patients dependent on dialysis unless their disease is accompanied by lung haemorrhage or early transplantation is required. Conversely, early diagnosis is mandatory if treatment is to conserve effectively renal function.

The mechanisms underlying the development of antiglomerular basement membrane antibodies await elucidation. Susceptibility to disease, however, appears to be conferred by possession of the HLA antigen DR2. ${ }^{14}$ Other factors that have been suggested to initiate the production of antibodies include influenza virus ${ }^{15}$ and exposure to volatile hydrocarbons. ${ }^{16}$ Smoking may exacerbate injury to tissues in the lungs of patients with circulating autoantibody. ${ }^{17}$ The notable seasonal variation that we noted suggests that certain viral infections may be important in either promoting formation of antibody or initiating injury to tissues.

In conclusion, we think that early diagnosis, intensive treatment, and the ability to tailor treatment to concentrations of pathogenic autoantibody have led to a substantial improvement in the prognosis of this previously rapidly fatal disease.

We thank all those doctors who made this study possible by kindly providing us with data on their patients; Miss S Goodwin for excellent secretarial help; and Dr A M Davison for allowing us to report data included in the Medical Research Council Glomerulonephritis Registry.

\section{References}

1 Lerner RA, Glassock RJ, Dixon FJ. The role of antiglomerular basement membrane antibody in the pathogenesis of human glomerulonephritis. $\mathcal{F}$ Exp Med 1967;126:989-1004.

2 Wilson CB, Marquardt H, Dixon FJ. Radioimmunoassay (RIA) for circulating antiglomerular basement membrane (GBM) antibodies. Kidney Int 1974;6:114a

3 Lockwood CM, Amos N, Peters DK. Goodpasture's syndrome: radioimmunoassay for measurements of circulating anti-GBM antibody. Kidney Int 1979;16:93a.

4 Bowman C, Lockwood CM. Clinical application of a radio-immunoassay for auto-antibodies to glomerular basement membrane. $\int$ Clin Lab Immunol (in press).

5 Lockwood CM, Rees AJ, Pearson TA, et al. Immunosuppression and plasma-exchange in the treatment of Goodpasture's syndrome. Lancet 1976;i:711-5.

6 Wilson CB, Dixon FJ. The renal response to immunological injury. In: Brenner BM, Rector FC, eds. The kidney. 2nd ed. Philadelphia: Saunders, 1981:1237-350.

7 Pusey CD, Lockwood CM, Peters DK. Plasma exchange and immunosuppressive drugs. Int $\mathcal{J}$ Artif Organs 1983;6:15-8.

8 Pusey CD. Glomerulonephritis due to autoantibodies to the glomerular basement membrane; treatment with plasma exchange. Medical Grand Rounds 1982;i:67-74.

9 Rees AJ, Lockwood CM, Peters DK. Enhanced allergic tissue injury in Goodpasture's syndrome by intercurrent bacterial infection. Br Med f 1977;ii:723-6.

10 Border WA, Baehler RW, Bhathena D, Glassock RJ. IgA antibasement membrane nephritis with pulmonary hemorrhage. Ann Intern Med 1979;91:21-5.

11 Wilson CB, Dixon FJ. Anti-glomerular basement membrane antibody-induced glomerulonephritis. Kidney Int 1973;3:74-89.

12 Wilson CB. Nephritogenic antibody mechanisms involving antigens within the glomerulus. Immunol Rev 1981;55:257-97.

13 Briggs WA, Johnson JP, Teichman S, et al. Antiglomerular basement membrane antibodymediated glomerulo-nephritis and Goodpasture's syndrome. Medicine 1979;58:348-61.

14 Rees AJ, Peters DK, Compston DAS, Batchelor JR. Strong associated between HLA-DRW 2 and antibody-mediated Goodpasture's syndrome. Lancet 1978;: $966-8$.

15 Wilson CB, Smith RC. Goodpasture's syndrome associated with influenza A2 virus infection. Ann Intern Med 1972;76:91-4.

16 Churchill DN, Fine A, Fault MH. Association between hydrocarbon exposure and glomerulonephritis. An appraisal of the evidence. Nephron 1983;33:169-72.

17 Donaghy $M$, Rees AJ. Cigarette smoking and lung haemorrhage in glomerulonephritis caused by autoantibodies to glomerular basement membrane. Lancet 1983;ii:1390-3.

(Accepted 15 October 1985) 